is, of course, not denied. We have the familiar examples of the employment of stone projectile points for drills, reamers and scrapers.

The quite obvious advantages of the large or "broad-head" type of arrow point for killing large game are likewise not disputed. In fact, stone points which might serve this purpose are quite common in Maine shell-heaps and the iron "trade" points found in these sites are notably large for arrow points. On the other hand, in view of the prevalence in New England of very minute stone points, and others made as long and narrow as it was possible to make them of such material, it seems clear that points not especially well adapted for killing large game, were widely employed. I have no information as to the incidence of very small stone points in the Maine shell-heaps beyond the fact that small narrow forms have been found that would make no greater wounds than a moderate-sized bone point. Further than expressing reasons for concluding that they were projectile points, I am not aware that I have implied any specialized usage of the simple bone points.

The apparent absence of these objects in sites away from the coast in contrast with their frequency in shell-heaps, may be accounted for by the perishable nature of bone except under certain conditions, as for example those furnished in shell deposits. If numbers of bone artifacts of other types were to be found in interior sites, only then would the absence of the simple bone point be significant. It is quite possible that some future discovery may throw new light on the subject and show that simple bone points were employed for quite another purpose than for projectile points, but with the information at hand the latter hypothesis appears to furnish the most probable explanation.

\author{
ERnest E. Tyzzer \\ Harvard Medical School \\ Boston, Massachusetts
}

\title{
Southwestern Trade in Shell Products
}

In the article: $A$ Shell Bracelet Manufactory, by Arthur Woodward, which appeared in the October, 1936, issue of this journal (Vol. II, No. 2, pp. 117125), Mr. Woodward states that the origin of Glycimeris shell artifacts found over the Southwest "has not been established." Although Dr. Sauer and I did not explicitly mention (in our report of 1931) the Boquillas and other west Sonoran sites as presumptive shell gorget and bracelet manufacturing centers, and as sources for trade to the north and east, this was implicit in the printed discussion, and was certainly in our minds at the time of discovery. Furthermore, concrete expression was given to these propositions in my article: Prehistoric Trade in the Southwest. ${ }^{210}$ The following quotations from this article contain the pertinent material:

"Sea shells are the best markers of long prehistoric trade routes in the South-

${ }^{210}$ New Mexico Business Review, Vol. 4, No. 4, pp. 202-209, Oct., 1935. 
west. This is because large numbers were used, and they have been found in almost continuous distribution from unmistakable points of origin on the coasts of the Californias, Sonora, Texas, and Tamaulipas to hundreds of localities in the interior Southwest. Although the Indians of the Southwest did not use sea shells as money (as did Old World peoples with the cowry, Northwest Indians with dentalium, and Atlantic Coast Indians with peak or wampum of clams, etc.), nevertheless sea shells were and are highly prized as personal ornaments. Distance from sources was a selective factor in the kinds of shells found most commonly at various Southwestern sites, and also found expression in a zonal arrangement of absolute quantity. Haliotis (abalone) shells, obtained only from the Pacific Coast, are found more commonly in California and Arizona than in New Mexico and Chihuahua. Glycimeris, Conus, and Olivella shells decrease in quantity from Sonora and Chihuahua sites (where they are very abundant), through southern Arizona and New Mexico (where they are fairly common), to sites in northern Arizona and New Mexico, and in Utah and Colorado (where all species of sea shells are rather uncommon). According to conchological determination of species of sea shells represented in Southwestern sites, probably all Haliotis shells came from the Pacific coast of California; the Glycimeris (Pectunculus) shells originated in the Gulf of California; Olivella and Conus shells, according to species, came from either the Pacific or Atlantic. In addition to the above mentioned species of sea shells, various Pectens, Strombus, Turritella, and Nassa are found in Southwestern sites in varying numbers which normally reflect distance from the source. The Indian trader was evidently conservative of his energy, for practically never have the 'blanks,' or portions of shells rejected in elaboration, been discovered in sites in Arizona, New Mexico, and Chihuahua. That this feature, which has puzzled numerous archaeologists, represents rough elaboration of the shell near the sea coast was determined by Professor Sauer, of the University of California, and the writer through the discovery of several sites near the Gulf of California Coast of Sonora which contained thousands of 'blanks'-mainly of Glycimeris." (pp. 203-204.)

"Trade routes can be plotted fairly accurately on a large scale map, through following the distribution of such 'trail markers' as a continuous but diminishing number of Middle Gila Polychrome potsherds from the Upper Gila near Virden, up the Animas drainage line, across the San Luis Basin into Chihuahua, down the Nogales and Huerigos drainages to the Carretas, down the Carretas and across the Ramos plains to the Casas Grandes, and thence diffused over the northwestern Chihuahua culture area. Similarly, trade routes for peoples of the Mimbres, Little Colorado, El Paso Polychrome, Chupadero, and other cultures can be traced through the distribution of typical potsherds. The marked association of turquoise with Mimbres wares, and later with Middle Gila wares, in southern New Mexico and northern Chihuahua indicates that turquoise from the Burro Mountains was first a Mimbres monopoly which was later taken over by the Middle Gila Polychrome people. This assumption 
is strengthened by the finding of Middle Gila Polychrome pottery in horizons above Mimbres material at sites in and near the Burro Mountains. The trade in Gulf of California sea shells, however, is not marked by potsherds of Sonora cultures advancing into Chihuahua and New Mexico, but by the distribution of Casas Grandes Polychrome ware nearly to the Gulf. Either Chihauhuans carried ceramic wares to such shell-ornament 'factories' as Boquillas near Las Trincheras to exchange for Glycimeris, etc., or Sonorans packed the shells to Chihuahua culture communities in the Bavispe drainage where they obtained the beautiful Casas Grandes vessels. There was no trade in Sonoran ceramics, as these were greatly inferior on all counts to Chihuahua wares." (p. 208.)

I fail completely to understand Mr. Woodward's belief that his interpretation (pp. 119-120) of the village deposit at the Boquillas or La Playa site differs from that presented by Dr. Sauer and myself. If he will re-read the relevant paragraphs (pp. 117-118 of the quotation; pp. 93-94 of the original) he will note that only the riprap on the tops of the occasional three-foot mounds is considered as resting in situ, and that the bulk of stone and artifact material is held to have been redeposited through the denudation and reduction of the general area by sheet floods. Especially note the statement, "We concluded therefore that the mounds, mostly elongated in the axis of the valley are the result of sheet flood erosion, that the entire surface since its habitation has been lowered about three feet by sluicing, with the exception of certain small surfaces protected by a riprap of rock." It should be added that there probably occurred a period of deposition over the entire site, after it had been abandoned, before erosion and denudation began their work.

Apropos of Mr. Woodward's statement, in the second whole paragraph of page 120 , there was no confusion in the identification of the small manos. The stones so identified carried definite evidence of use as grinding tools, with no surfaces indicating a percussion use.

I should like to bring up one more point for consideration by all Southwestern archaeologists. Just how numerous actually are the legged vessels from the Gila valley, and elsewhere in the Southwest, which have been cited so of ten as evidence for Central Mexican influence? I am referring to vessels which have been purposely legged as a support mechanism (Mexican type), and not to those where the legs are pertinent to the representation of some animal. So far as I have been able to find, the examples cited by Vaillant (1932) from Fewkes (1912), Gladwin (1930), and Woodward (1931), cover the field of published and illustrated finds. One would gather from the literature, and an examination of museum material, that legged wares are exceedingly rare in the Southwest, and are predominantly undecorated. The writer would appreciate very much the citation of authentic prehistoric legged vessels from the Southwest, if any additional examples are known.

Donald D. Brand

University of New Mexico

Albuquerque, New Mexico 